\title{
Conflict resolution in socially housed Sumatran orangutans (Pongo abelii)
}

\author{
Kathrin S. Kopp ${ }^{\text {Corresp., }}{ }^{1}$, Katja Liebal ${ }^{1}$ \\ ${ }^{1}$ Department of Education and Psychology; Comparative Developmental Psychology, Freie Universität Berlin, Berlin, Germany \\ Corresponding Author: Kathrin S. Kopp \\ Email address: kathrin.kopp@fu-berlin.de
}

Background. Peaceful conflict resolution strategies have been identified as effective mechanisms for minimising the potential costs of group life in many gregarious species, especially in primates. The knowledge of conflict-management in orangutans, though, is still extremely limited. Given their semisolitary lives in the wild, there seems to be barely a need for orangutans to apply conflict management strategies other than avoidance. However, because of the rapid loss of orangutan habitat due to deforestation, opportunities to prevent conflicts by dispersion are shrinking. Additionally, more and more orangutans are brought into rehabilitation centres where they are bound to live in close contact with conspecifics. This raises the question, whether and how orangutans are able to cope with conflicts, which are inevitably connected with group life.

Methods. Observational zoo-studies provide a valuable method to investigate such potential: In zoos, orangutans usually live in permanent groups and face the challenges of group life every day. Therefore, we observed a group of six socially-housed Sumatran orangutans at the Dortmund Zoo, Germany, both in their spacious outdoor enclosure in the summer and in the less spacious indoor enclosure in the winter. During $157.5 \mathrm{~h}$ of observation, we collected data on aggressive interactions, third-party interventions and post-conflict affiliations. We applied the post-conflict/matched-control observation (PC/MC) and the time rule method to investigate the occurrence of reconciliation and post-conflict third-party affiliations.

Results. We recorded a total of 114 aggressive interactions (including conflicts in the context of weaning and of male sexual coercion). As expected, we found an increase of both open conflicts and peaceful conflict resolution under less spacious conditions. In accordance with previous reports, we observed interventions by initially uninvolved individuals. Whereas we found no clear evidence for post-conflict third-party affiliations, we were able to demonstrate the occurrence of reconciliation among orangutans.

Discussion. Notwithstanding the small sample size and the explorative character of our study, we found evidence that orangutans possess a potential for prosocial conflict resolution. When living in groups and under conditions in which dispersion is no longer an option, orangutans are capable to flexibly apply strategies of conflict resolution to cease open conflicts and to repair the potential social damage of aggressive interactions. These strategies are similar to those of other great apes. 
1 Conflict resolution in socially housed Sumatran orangutans (Pongo abelii)

2 Kathrin S. Kopp ${ }^{1} \&$ Katja Liebal ${ }^{1}$

$3{ }^{1}$ Dep. of Education and Psychology, Div. Comparative Developmental Psychology, Freie

4 Universität Berlin, Berlin, Germany

5

6

7 Corresponding Author:

8 Kathrin S. Kopp ${ }^{1}$

9 Habelschwerdter Allee 45; 14195 Berlin; Germany

10 E-Mail: kathrin.kopp@,fu-berlin.de 
11 Background. Peaceful conflict resolution strategies have been identified as effective

12 mechanisms for minimising the potential costs of group life in many gregarious species,

13 especially in primates. The knowledge of conflict-management in orangutans, though, is still

14 extremely limited. Given their semi-solitary lives in the wild, there seems to be barely a need for

15 orangutans to apply conflict management strategies other than avoidance. However, because of

16 the rapid loss of orangutan habitat due to deforestation, opportunities to prevent conflicts by

17 dispersion are shrinking. Additionally, more and more orangutans are brought into rehabilitation

18 centres where they are bound to live in close contact with conspecifics. This raises the question,

19 whether and how orangutans are able to cope with conflicts, which are inevitably connected with

20 group life.

21 Methods. Observational zoo-studies provide a valuable method to investigate such potential: In

22 zoos, orangutans usually live in permanent groups and face the challenges of group life every

23 day. Therefore, we observed a group of six socially-housed Sumatran orangutans at the

24 Dortmund Zoo, Germany, both in their spacious outdoor enclosure in the summer and in the less

25 spacious indoor enclosure in the winter. During $157.5 \mathrm{~h}$ of observation, we collected data on

26 aggressive interactions, third-party interventions and post-conflict affiliations. We applied the

27 post-conflict/matched-control observation $(\mathrm{PC} / \mathrm{MC})$ and the time rule method to investigate the

28 occurrence of reconciliation and post-conflict third-party affiliations.

29 Results. We recorded a total of 114 aggressive interactions (including conflicts in the context of

30 weaning and of male sexual coercion). As expected, we found an increase of both open conflicts

31 and peaceful conflict resolution under less spacious conditions. In accordance with previous

32 reports, we observed interventions by initially uninvolved individuals. Whereas we found no

33 clear evidence for post-conflict third-party affiliations, we were able to demonstrate the

34 occurrence of reconciliation among orangutans.

35 Discussion. Notwithstanding the small sample size and the explorative character of our study, 36 we found evidence that orangutans possess a potential for prosocial conflict resolution. When

37 living in groups and under conditions in which dispersion is no longer an option, orangutans are

38 capable to flexibly apply strategies of conflict resolution to cease open conflicts and to repair the 39 potential social damage of aggressive interactions. These strategies are similar to those of other 40 great apes. 
42

43

44

\section{Introduction*}

When de Waal and van Roosmalen (1979) published their seminal study on reconciliation and consolation in chimpanzees (Pan troglodytes), they initiated a shift in perspective in the research on conflicts: from focussing primarily on aggression to investigating conflict situations and how they are managed (Aureli \& de Waal, 2000b). Conflicts of interest regarding, e.g., limited resources such as food or mating partners (Janson, 1988; Robbins, 2008) may potentially result in direct costs including loss of resources or injuries, but also in indirect costs by jeopardising valuable social relationships (Aureli \& de Waal, 2000b; Kummer, 1978). Given that long-term relationships are crucial for the exchange of benefits within primate groups (Furuichi \& Ihobe, 1994; Langergraber, Mitani \& Vigilant, 2009; Mitani, 2009; Seyfarth \& Cheney, 2012), their endangerment might be even more disadvantageous to an individual than the immediate costs. Conflicts may also destabilise of the whole group, when social networks are affected (Flack et al., 2006).

To minimise the costs, a variety of conflict management mechanisms have evolved across groupliving species (Aureli \& de Waal, 2000a). These mechanisms include prosocial conflict resolution, such as interventions by third parties and post-conflict affiliations either between the opponents (reconciliation) or between an opponent and a third party (post-conflict third-party affiliation or PCTA) (Judge, 2003). Prosocial conflict resolution may have several, not necessarily mutually exclusive functions, e.g.: protecting valuable partners and stabilising or restoring valuable relationships (e.g. Aureli, Cords \& van Schaik, 2002; Cords \& Killen, 1998; Kutsukake \& Castles, 2004; Palagi, Paoli \& Borgognini Tarli, 2004; Silk, 2002; Wittig et al., 2007), reducing conflict-related anxiety in the involved individuals (e.g. de Waal \& Aureli, 1997; Fraser, Stahl \& Aureli, 2008; Romero \& de Waal, 2010) or maintaining group cohesion (Flack et al., 2006).

Much of our knowledge comes from studies on the African great ape species, especially chimpanzees (Pan troglodytes) and bonobos (Pan paniscus), who regularly engage in third-party intervention, reconciliation and PCTA (e.g. Fraser \& Aureli, 2008; Palagi \& Norscia, 2013; Palagi et al., 2004; Rudolf von Rohr et al., 2012). Their social systems are characterised by a

\footnotetext{
* Annotation: The present article, including most of the figures and tables, is largely based on Chapter 2.3 of the dissertation of the first author (Kopp, 2017)
} 
70 large community size, multimale/multifemale groups and a high degree of fission-fusion 71 dynamics demonstrating social flexibility (Aureli et al., 2008). Social bonds, reciprocity and cooperation play a central role in both species (Boesch, 1994; Furuichi \& Ihobe, 1994; Jaeggi et al., 2013; Langergraber et al., 2009; Mitani, 2009). Hence, an important function of conflict resolution in these species most likely consists in stabilising and restoring valuable relationships (de Waal \& Aureli, 1997). Gorillas (Gorilla spp.) live in smaller, more stable and cohesive, predominantly one-male harem groups (Parnell, 2002; Robbins, 1995); and male interventions in conflicts among females as well as affiliative post-conflict contacts are common (Cordoni, Palagi \& Borgognini Tarli, 2006; Scott \& Lockard, 2007; Watts, 1995a; Watts, 1995b; Watts, 1997).

In contrast, our knowledge about conflict resolution in the Asian great apes, the various species of orangutans (Pongo spp.), is very limited. Although the social organisation of orangutans has been characterised as an individual-based fission-fusion society (van Schaik, 1999), orangutans are largely known as semi-solitarily living species with a mean party size of less than two individuals (Delgado \& van Schaik, 2000). However, sociability varies between the species, with Sumatran orangutans (Pongo abelii) being generally more gregarious than Bornean orangutans (Pongo pygmaeus), but also within a species or over time (Delgado \& van Schaik, 2000; Husson et al., 2009; van Schaik, Marshall \& Wich, 2009). For example, in periods of high fruit abundance, orangutans may aggregate in large fruit trees and occasionally form travel bands (Delgado \& van Schaik, 2000). Adult females and their dependent offspring live in large, overlapping home ranges, which overlap with the larger home range of a resident flanged male (Singleton et al., 2009; van Schaik, 1999). In contrast to other great apes, orangutan females are the philopatric sex (Arora et al., 2012; van Noordwijk et al., 2012), i.e. females tend to stay in their natal area, whereas mature males disperse (Mitra Setia et al., 2009). Maternally related females with dependent offspring associate with each other and tolerate or even enable social play among their offspring (van Noordwijk et al., 2012). At some sites, they are unusually tolerant among each other, feed in close proximity and even share food (Singleton \& van Schaik, 2002; van Schaik, 1999). Females and males temporarily engage in consortships, characterised by coordinated traveling, cooperative mating and other social interactions (Utami Atmoko et al., 2009a), however, forced copulations occur often - especially by unflanged males. 
99

100

101

102

103

104

105

106

107

108

109

110

111

112

113

114

115

116

117

118

119

120

121

122

123

124

125

126

127

In sum, recent findings suggest that orangutans are not as solitary as suggested and that social relationships might play a more important role, especially among females, than previously assumed, raising the question whether conflict resolution might be present also in orangutans.

However, there is almost no evidence that wild orangutans apply conflict management strategies other than avoidance. This strategy is most obvious for sexually mature (flanged) males, but also for adult females. Flanged males are highly intolerant of other flanged males, probably due to high mating competition, and rarely encounter each other, although their large home ranges overlap. If encounters occur, they are inevitably agonistic and often result in injuries or even death (Utami Atmoko et al., 2009b). Associated unrelated females show more aggressions among each other than related females. These aggressions usually result in breaking up the association; related females, on the other hand, show more social tolerance (van Noordwijk et al., 2012).

The only report of a form of prosocial conflict resolution in the wild refers to a case, when a female Bornean orangutan received protection from a flanged male, who intervened actively, though non-aggressively, in a sequence of severe, finally lethal attacks by another female and an unflanged male (Marzec et al., 2016).

However, given the rapid loss and fragmentation of orangutan habitat due to deforestation, the opportunities to prevent conflicts by dispersion are shrinking (Nellemann et al., 2007).

Additionally, as a consequence of habitat loss, poaching and illegal pet trade, a growing number of orangutans are destined to live in rehabilitation centres in close contact with conspecifics, partly under overcrowded conditions (Russon, 2009). Therefore, the question as to whether and how orangutans are capable of coping with inter-individual conflicts, which are unavoidably connected with group life, needs to be answered. A better understanding of these capabilities may also improve the welfare of orangutans living in rescue centres or zoos due to adjusted husbandry conditions.

To tackle this problem, observational zoo-studies provide a valuable approach to investigate the conflict resolution potential in question. In modern zoos, orangutans are mostly kept in permanent groups, usually comprising one adult male, several adult females and their offspring. Whereas this group structure accounts for the natural dispersal strategy of male orangutans 
128 (Knott, 2009), it simultaneously precludes any interactions among flanged males as well as any

129 female partner choice. Furthermore, these groups often comprise unrelated females.

130 Despite these differences of social life between natural and captive conditions, captive

131 orangutans generally seem to cope surprisingly well with group life, and open conflicts are rare.

132 Zoo-living orangutans engage in social play and other affiliative interactions (Edwards \&

133 Snowdon, 1980; Zucker et al., 1986; Zucker, Mitchell \& Maple, 1978), they develop social

134 bonds even among not kin-related individuals, and share food selectively with close social

135 partners (Kopp \& Liebal, 2016). Group living orangutans tend to communicate over food and to

136 share frequently when provided with a monopolisable food source (Kopp, 2017; Kopp \& Liebal,

137 2016; Liebal \& Rossano, 2017), which demonstrates their ability to mitigate conflicts by tolerant

138 and prosocial behaviour. Considering these findings on the one hand and the phylogenetic

139 proximity between orangutans and the other great ape species on the other hand, group-living

140 orangutans should also be able to cease conflicts, to reconcile and/or engage in PCTAs with

141 close and/or valuable social partners after open conflicts.

142 However, to date, conflict resolution among captive orangutans has been neglected by scientific

143 research - apart from very few reports on third-party interventions (Tajima \& Kurotori, 2010;

144 Zucker, 1987). With this observational study, we aim to fill this gap and postulate the following

145 hypothesis:

$146 \mathrm{H}$ : The behavioural repertoire of orangutans includes strategies of conflict resolution that are

147 similar to those of the other great apes. Group-living orangutans use these strategies in order to

148 reduce direct and indirect costs of open conflicts.

149 We derived the following predictions:

150 (P1) If there is the opportunity to avoid confrontations, open conflicts should be rare. With

151 decreasing available space, both open conflicts and conflict resolution are expected to increase in 152 frequency.

153 (P2) Third parties are expected to intervene in aggressive interactions, especially when they are

154 highly intense and/or a valuable social partner is involved. 
155 (P3) Immediately after a conflict, former opponents are expected to engage in affiliative contacts 156 with each other.

157 (P4) Immediately after a conflict, an increased number of affiliative contacts between former 158 victims and third parties are expected.

159 Findings meeting these expectations would provide evidence for conflict resolution behaviours 160 in orangutans being similar to those found for other great apes. Therefore, they would further 161 support the more general hypothesis that conflict resolution has evolved in a common ancestor of 162 all extant hominids.

163

164

165

166

167

168

169

170

171

172

173

174

175

176

177

178

179 180

\section{Materials and Methods}

\subsection{Study group and housing conditions}

Observations were conducted on a group of six Sumatran orangutans at the Dortmund Zoo, Germany, consisting of one adult male and three adult females, one of them with two offspring: one not fully weaned, semi-dependent female and one unweaned, dependent female (Table 1).

In the summer, all individuals were kept together in the large grassy outdoor enclosure $\left(1515 \mathrm{~m}^{2}\right)$ during day time, featuring trees, bushes, herbs, climbing structures with ropes, a tree hut and a fresh water spring. During the winter, the individuals were kept in two subgroups (Table 1) for zoo management reasons. The subgroups were housed in two adjacent indoor enclosures $\left(65 \mathrm{~m}^{2}\right.$ and $48 \mathrm{~m}^{2}$ ), each with additional night boxes and alternating temporary access to a third indoor compound $\left(140 \mathrm{~m}^{2}\right)$. Subgroup A consisted of the male Walter, the female Toba and their two daughters Tao and Eirina; subgroup B consisted of the two unrelated females Suma and Djamuna. All indoor enclosures were covered with a steel mesh and equipped with climbing structures and ropes, poking timber and access to water. An additional mesh, which separated the enclosures, provided the opportunity for orangutans to reach through with their hand (adults) or arm (immatures). Both subgroups, therefore, had - and frequently used - the opportunity to interact with each other through the mesh, e.g., by exchanging food or non-food items, sitting in body contact, playing or even mating (see also Kopp, 2017, pp. 47, 58; Kopp \& Liebal, 2016). 
181 Aggressive interactions were also possible, including grabbing body parts or pulling their fur,

182 hitting, biting or chasing each other across the mesh.

183 The main diet consisted of a mixture of vegetables and fruits, supplemented by, e.g., leafy

184 branches, yoghurt, cooked eggs and meat and special items for behavioural enrichment. Feeding 185 times did not change depending on the housing conditions.

186

187

188

189

190

191

192

193

194

195

196

197

198

199

200

201

202

203

204

205

206

207

208

209

\subsection{Data collection and coding}

Group observations were conducted over a total of 30 days during September 2011, February/March 2012 and June/July 2012, with an average observation time of $5.25 \mathrm{~h}$ per day. Using a digital camcorder CANON Legria FS200, the whole group was continuously video recorded by KK. This produced $157.5 \mathrm{~h}$ of footage in total, of which $74.35 \mathrm{~h}$ had been collected outdoors and $83.15 \mathrm{~h}$ indoors. The filming sessions were evenly distributed over the daily main activity period in order to cover all situations typically occurring in the group.

Data were coded using Microsoft Excel ${ }^{\circledR} 2010$ and the coding software INTERACT® Vers. 14.3. We considered all aggressive interactions and interventions by third parties as well as all post-conflict affiliative interactions, the latter occurring both between the former opponents (reconciliation) and between the victim and a third party (post-conflict third-party affiliation, PCTA). To code aggressive interactions and third-party interventions, we applied all occurrences sampling as the sampling rule (Altmann, 1974).

An aggressive interaction was defined as an interaction between two or more individuals that comprised an initial aggression by an individual and a respective reaction by a target individual. Aggression was defined as a directed behaviour of an individual (aggressor) towards a group member (victim) that resulted in physical harm or signalled the readiness to harm (adapted from Aureli \& de Waal, 2000a, p. 387). To determine whether an interaction such as wrestling or chasing was playful or aggressive, the reaction of the target individual was taken into account. If the behaviour in question caused distress of the recipient, expressed, for example, by piloerection or vocalisations such as kiss squeaks, whimpering and screaming, or avoidance and resistance behaviour, this behaviour was coded as aggressive. With regard to the intensity of an aggression, we distinguished low, medium and high levels of aggression. When an aggression consisted not of a single behaviour, but of a combination of several behavioural elements, its 
210 level of intensity was categorised with regard to the most intense constituent. A reaction to an

211 aggression could consist of a single behaviour or a combination of behaviours belonging to one

212 of four categories: avoidance, non-aggressive behaviour intended to cease the attack, aggressive

213 behaviour against the initial aggressor, i.e. counter-aggression, or against an uninvolved third

214 party, i.e. redirection (Aureli \& de Waal, 2000a, 387). We defined a third-party intervention as

215 the attempt of an initially uninvolved individual (or individuals) to cease an ongoing open

216 conflict through peaceful behaviour, e.g. appeasement behaviour, shielding the victim or

217 separating the opponents, or aggressive behaviour, e.g. attacking the aggressor (for details, see

218 coding scheme, Fig. S1).

219 To code the victim's affiliative post-conflict contacts, we combined behavioural and focal

220 sampling (Altmann, 1974) and applied the post-conflict/matched-control observation method

221 (PC/MC method, de Waal \& Yoshihara, 1983). Any kinds of friendly interactions were coded,

222 such as contact sitting, embracing, social play, food sharing, grooming or gently touching. We

223 also determined who initiated the affiliative contact.

224 For PC observations, recordings of the first $10 \mathrm{~min}$ following an aggressive interaction were

225 coded with a focus on the victim. The victim's first affiliative contacts with the former aggressor,

226 on the one hand, and with an uninvolved individual, on the other, were coded. To determine the

227 latency of their occurrence with respect to the end of the aggression, the respective one-minute

228 time interval in the PC period was assigned to each first affiliative contact. In case the conflict

229 had been resumed within the first 3 min of the PC period, we stopped this PC and began a new

230 PC immediately following the end of the resumed aggressive interaction. Each PC was paired

231 with a particular MC. For MC observations, we examined the video material recorded on the

232 next possible day for 10 min to code the first affiliative contacts of the former victim with the

233 former aggressor and with a third party, respectively. These observations were usually conducted

234 on the very next day at exactly the same time; if this was not possible, we did so within a time

235 slot of maximum +/- 60 min with regard to the onset of the exactly matched time. If the

236 necessary next-day MC recording was not available, we used time-matched video footage of

237 observations on a previous or following day within a maximum time window of $+/$ - seven days.

238 If a conflict had taken place within 10 min prior to the planned MC interval, we chose the

239 interval nearest to the matched time, within a time slot of maximum $+/-60 \mathrm{~min}$, which followed 
240 an interval without conflict of at least $10 \mathrm{~min}$. Applying this method resulted in PC-MC pairs,

241 which were analysed as described in the following section.

\section{$242 \quad 2.3 \quad$ Data analysis}

243 All statistical computations were conducted by using statistics software R vers. 3.4.1 (R Core

244 Team, 2017) with additional packages, e.g. car (Fox \& Weisberg, 2011) and sfsmisc (Maechler

245 et al., 2016) (for more details, see below). Statistical significance was assessed at the $\alpha$-level of $246 \quad 0.05$.

247 (i) Aggressive interactions and third-party interventions

248 In a first step, we calculated the frequencies of aggressive interactions with regard to context, 249 intensity and the identity of the opponents.

250 To test for an effect of the housing conditions on the occurrence of aggressions, we computed the 251 aggression rates per hour for outdoor $(74.35 \mathrm{~h})$ and indoor observation $(83.15 \mathrm{~h})$ for each

252 individual. Assuming that the aggression level would rise under less spacious conditions, we 253 conducted an exact one-tailed Wilcoxon signed rank test using the $\mathrm{R}$ function wilcox.exact from 254 the R package exactRankTests (Hothorn \& Hornik, 2015).

255 We conducted a weighted social network analysis (Fruchterman-Reingold algorithm) in order to 256 visualise behavioural patterns of aggressions within and between individuals separately for the 257 two housing conditions, by using the R packages igraph (Csardi \& Nepusz, 2006) and tnet 258 (Opsahl, 2009).

259 For possible effects of the housing conditions on the intensity of aggressions and the occurrence 260 of third-party interventions, we conducted Fisher's exact tests that account for a small sample

261 size using R function fisher.test. If possible, we calculated odds ratios. To control for influential 262 individuals, we ran Fisher's exact tests for independence. When no significant correlation 263 between individuals and the distribution for outdoor and indoor enclosure could be detected, we 264 considered both variables as independent, i.e. the effect as being not driven by particular 265 individuals. We also investigated whether the mesh - separating the subgroups indoors and 266 through which many aggressions occurred - might have had an effect on the frequency of 
267 aggression. For that purpose, we ran a Fisher's exact test of independency on pooled data (indoor 268 vs. outdoor; separated dyads vs. not separated dyads).

269 Forced copulations represent a specific class of aggression in orangutans, which is uncommon in other non-human great apes. Therefore, we separated these cases from aggressions in other contexts and considered both subsets separately in the further analyses.

272 Due to the rare occurrence of intervened conflicts, inferential statistics on an individual level 273 were not possible. Therefore, we applied descriptive statistics. In order to test whether the more 274 limited space would increase the probability of third-party interventions, we conducted a Fisher's exact test on pooled data and calculated the odds ratio.

276

(ii) Affiliative post-conflict contacts

277

278

In a next step, we examined whether and how conflicts altered the subsequent behaviour between the opponents as well as between other group members and the victim (Veenema, Das \& Aureli, 1994). In particular, we were interested in whether reconciliation and/or post-conflict third-party affiliation occurred. Reconciliation was defined here generally as the affiliative reunion of the opponents evoked by the respective conflict. Post-conflict third-party affiliation (PCTA) was defined here generally as the first affiliative interaction between a previously uninvolved individual and the former victim evoked by the respective conflict, regardless of the identity of the individual who initiated the contact.

To investigate whether reconciliation or PCTA occurred, we combined two well-established methods as recommended by Veenema (2000): the PC/MC method (de Waal \& Yoshihara, 1983) and the time rule method (Aureli, van Schaik \& van Hooff, 1989). Both methods have their advantages: whereas the PC/MC method controls for inter-individual differences by comparing PC and MC for the particular dyads, the time rule method allows for an operational definition of reconciliation by determining a relevant time window following a conflict (Veenema, 2000, p. 22).

\section{PC/MC method}

We differentiated between the following types of PC-MC pairs (de Waal \& Yoshihara, 1983): A PC-MC pair was attracted if the affiliative interaction took place earlier in the PC than in the 
$295 \mathrm{MC}$, or only in the PC. If the affiliative contact took place earlier in the MC than in the PC, or 296 only in the MC, then it was categorized as dispersed, and as neutral if either the affiliative 297 interaction occurred in both observation intervals at the same time, or did not occur at all.

298 Following de Waal and Yoshihara (1983), a significantly higher proportion of attracted vs. 299 dispersed PC-MC pairs would demonstrate the occurrence of reconciliation or of PCTA in the 300 study group. To test this, we conducted exact Wilcoxon signed rank tests on the proportions for 301 attracted and dispersed pairs for each focal individual (Fraser \& Aureli, 2008, p. 1116), using the $302 \mathrm{R}$ function wilcox.exact from the R package exactRankTests (Hothorn \& Hornik, 2015). We 303 included only those individuals who had received aggression at least three times.

Time rule method

305

306

307

308

309

310

311

312

313

314

315

316

317

318

319

320

321

322

323

As an alternative means of determining reconciliation and PCTA, which allows for an operational definition of both concepts (Aureli et al., 1989), we indicated for each PC-MC pair the respective one-minute intervals in which the first affiliative contacts between the opponents or between the victim and a third party occurred. Then we computed the cumulative distributions (i.e. the cumulated relative frequencies) over time for PC and MC. Following Aureli and colleagues (1989), we applied a two sample Kolmogorov-Smirnov test, using the R function ks.test to investigate whether the distributions differed. In case a significant difference could be demonstrated, we determined the time interval with the maximum difference between the cumulative relative frequencies of $\mathrm{PC}$ and $\mathrm{MC}$ to operationally define reconciliation. Following Aureli et al. (1989, p. 42), each affiliative post-conflict contact between former opponents or between the former victim and a third party occurring within this critical interval is considered as reconciliation and PCTA, respectively. We tested each time interval for a significant correlation between the observation period ( $\mathrm{PC}$ vs. $\mathrm{MC}$ ) and the cumulative frequency of affiliations using Fisher's exact test with $\mathrm{R}$ function fisher.test, This function also provided the respective odds ratios, of which we used the highest as a rational for determining the critical interval.

As suggested by Aureli and van Schaik (1991, p. 7), we controlled for the possibility that a difference between the cumulative distributions of PC and $\mathrm{MC}$ might be caused by extreme behaviour of single individuals. In order to test whether the variables observation period (PC vs. $M C$ ) and initiator of affiliative contacts were independent, we conducted a Fisher's exact test in 
324 which we included the observed frequencies of affiliative contacts within the critical time

325 interval for reconciliation. In case the test demonstrated no significant correlation, we concluded

326 that the found difference was not driven by extraordinary behaviour of particular individuals, but

327 reflected a general reconciliatory tendency.

328 Finally, we analysed whether particular types of affiliative behaviour between the former

329 opponents, on the one hand, and between the former victim and a third party, on the other, had

330 been more prevalent immediately after a conflict than without a preceding conflict. We

331 conducted Fisher's exact test and calculated odds ratios for pooled data. Additionally, we

332 controlled for influential dyads to check whether the found effect might have been driven by the

333 behaviour within particular dyads using a Fisher's exact test.

$334 \quad$ (iii) Inter-rater reliability

335 All coding was done by KK. To assess inter-rater reliability, a second person who was a trained

336 behavioural observer but naïve with regard to the hypothesis additionally coded $20 \%$ of the

337 aggressive interactions and respective PCs and MCs. The calculation of Cohen's kappa

338 coefficient ( $\kappa)$, using function kappa2 of R package irr (Gamer et al., 2012), revealed good

339 agreement between both raters (reconciliation: $\kappa=0.73, p<0.001$; PCTA: $\kappa=0.74, p<0.001$ ).

\section{$340 \quad 2.4 \quad$ Ethical Note}

341 We observed the orangutans in their usual enclosures from the visitors' area during the zoo's opening hours. There were no manipulations of any kind or changes of their daily routine due to our study. The directorate of Dortmund Zoo provided full approval for this purely observational research. IRB approval was not necessary because no special permission for including animals in purely observational studies is required in Germany (TierSchGes $§ 7$ and $\S 8$ ). The Zoo Dortmund is a member of the European Association of Zoos and Aquaria (EAZA) and of the World Association of Zoos and Aquariums (WAZA). Animal husbandry and research comply with the EAZA Minimum Standards for the Accommodation and Care of Animals in Zoos and Aquaria and the WAZA Ethical Guidelines for the Conduct of Research on Animals by Zoos and Aquariums. 


\section{Results}

\section{$352 \quad 3.1 \quad$ Aggressive interactions}

353 In total, we recorded 114 aggressive interactions, including 16 cases of coerced

354 copulations/copulation attempts and five counter-aggressions in the context of male sexual

355 coercion. Whereas 85 aggressions were distinct events with no other aggression following within

$3564 \mathrm{~min}$, the remaining 29 cases occurred in sequences of two, three or four causally connected

357 interactions.

358 Half of all aggressions were of medium intensity $(n=57,50 \%)$, followed by high intensity $(n=$

$35937,32.5 \%)$ and low intensity $(n=14,12.3 \%)$. In six cases $(5.3 \%)$, the intensity of aggression

360 could not be determined (for details, see Fig. SF2). Even during highly intense aggression, only

36116 out of 37 cases included bites or bite attempts. Only once, such an encounter resulted in a

362 minor injury of a victim's finger.

363 The victim's reactions most frequently consisted of single behaviours $(n=60)$ or of

364 combinations of up to four behaviours. The vast majority of these reactions were non-aggressive,

365 consisting mainly in avoidance (move away, $n=47$ ) or non-aggressive behaviours to cease the

366 conflict (withdraw body part/attempt to break free, $n=34$ ), frequently accompanied by

367 vocalisations. In nine cases, the victim showed no detectable reaction. Only 20 reactions

368 included aggressive behaviour, most of them in the context of male sexual coercion. There was

369 no case of redirection.

370 The majority of aggressions seemed to occur spontaneously ( $n=49,43 \%)$, i.e. without any

371 detectable reason, followed by aggressions in the contexts of sexual coercion $(n=26,23 \%)$ and

372 weaning $(n=17,15 \%)$. Aggression due to food or object competition occurred only rarely in

373 nine (8\%) and six cases (5\%), respectively. There was one case of third-party punishment. For

374 the remaining cases $(n=6,5 \%)$, the context was undeterminable due to limited visibility. Most

375 high-level aggressions occurred during sexual coercion $(n=16,43 \%)$, whereas most low-level

376 aggressions occurred in the context of weaning $(n=12,86 \%)$ (for details, see Fig. S2).

377 With regard to the different housing conditions during summer (outdoors) and winter (indoors), a

378 one-tailed exact Wilcoxon signed rank test comparing individual aggression rates showed that 
379 they significantly increased in indoor (median $=0.144)$ compared to outdoor $($ median $=0.020)$

380 conditions $(n=5, T=0, p=0.031)$. The probability for highly intense aggressions to occur was 3813.85 times higher indoors than outdoors (Fisher's exact test on pooled data, $p=0.04$ ). This effect 382 was not driven by the extreme behaviour of single individuals (Fisher's exact test, $p=0.588$ ).

383 Furthermore, although many indoor aggressions occurred through the mesh that separated the 384 subgroups (illustrated as a dashed line in Figure 1), we found no general aggression-encouraging 385 effect of the mesh (Fisher's exact test on pooled data, $p=1$ ).

386 Moreover, as Figure 1 illustrates, the frequency of aggressive interactions varied across 387 individuals with regard to the identity of the aggressor (indicated by the size of the vertices, i.e.

388 circles) and within individuals with respect to the identity of the recipient of the aggression 389 (indicated by the width of the respective edges, i.e. arrows). Aggressions did not occur 390 symmetrically within dyads, but were predominantly directed down the dominance hierarchy.

391 Toba, the highest-ranking female, performed most of the aggressions $(n=66,58 \%)$, which were 392 mainly directed towards Djamuna $(n=27)$, the lowest-ranking adult female. The second main 393 target of Toba was her older daughter Tao $(n=24)$; however, these conflicts mostly emerged in 394 the context of weaning and were usually of low intensity. Whereas Toba was the most frequent 395 aggressor, she only received aggressions from Walter (in cases of sexual coercion), but barely 396 from other females.

\section{$397 \quad 3.2 \quad$ Third-party intervention}

\section{$398 \quad$ 3.2.1 All contexts except male sexual coercion}

399 Across all contexts but male sexual coercion, one quarter $(n=22,24 \%)$ of the 93 aggressions 400 provoked an intervention by an uninvolved individual. In three of these cases, two individuals 401 402 intervened, resulting in a total of 25 interventions. In one further case, it was not determinable whether an intervention had taken place or not.

403 The majority of interventions did not include any agonistic behaviour $(n=17,68 \%)$. All 404 individuals but Djamuna peacefully intervened at least once, with Toba and Suma intervening 405 most frequently (seven and six times, respectively). Only eight interventions involved aggressive 406 behaviour, two of them were related to the same conflict: Toba attacked Djamuna five times in 407 support of one of her daughters; Toba was attacked twice by Suma and once by Walter, both 
408 supporting Djamuna. Individuals intervened selectively with respect to the victim's identity: e.g.

409 Toba exclusively interfered in aggressions directed against her daughters, whereas Suma

410 predominantly intervened when Djamuna had been the target of aggression (Fig. S3). There was

411 no case of agonistic support for the aggressor. All interventions but one by Tao were successful

412 and ceased the respective aggression.

413 With regard to housing conditions, the probability that conflicts caused an intervention was four 414 times greater indoors than outdoors (Fisher's exact test on pooled data: $p=0.025$, odds ratio $=$ 415 4.24). This effect was not driven by extreme behaviour of single individuals (Fisher's exact test: $416 p=0.322)$.

\section{$417 \quad$ 3.2.2 The context of male sexual coercion}

418 In contrast to other contexts, all 16 forced copulations or copulation attempts provoked at least 419 one intervention either by Toba, when Tao was the target, or by one or both of her daughters in 420 those cases in which Toba was the target. All of these interventions were physical attacks against 421 Walter, including mostly a combination of behaviours such as move between/shielding, grab, 422 pull, hit and bite. Whereas both interventions by Toba stopped the sexual aggression against Tao, 423 no intervention by the immatures was successful.

\section{$424 \quad 3.3 \quad$ Affiliative post-conflict contacts}

\section{$425 \quad$ 3.3.1 All contexts except male sexual coercion}

Post-conflict affiliations between opponents

427 We determined a total of 70 PC-MC pairs, of which 31 pairs were attracted, 23 pairs neutral and 42816 pairs dispersed. The remaining 23 cases of the 93 aggressive interactions could not be 429 included in the analysis because: (i) a further aggression occurred within $3 \mathrm{~min}(\mathrm{n}=12)$, (ii) a 430 PC- or MC-contact occurred, but was not specifiable due to limited visibility ( $\mathrm{n}=8)$, or (iii) 431 either PC or MC was not available $(\mathrm{n}=3)$. We calculated the proportion of attracted, dispersed and neutral PC-MC pairs for each victim. An exact Wilcoxon signed rank test (with Walter 433 excluded, as he had received only one aggression) demonstrated a significantly higher proportion 434 of attracted than of dispersed PC-MC pairs $(n=5, T=0, p=0.031)$. Thus, according to the $435 \mathrm{PC} / \mathrm{MC}$ method, reconciliation occurred within this study group (Figure 2). 
436 Applying the time rule method (Aureli et al., 1989) revealed that the majority of first affiliative

437 contacts between the former opponents occurred within the first one-minute interval following

438 the aggressive interaction (Figure 3.A). A comparison of the distribution of first affiliative

439 contacts between the former opponents demonstrated a significant difference between the PC-

440 and the MC-condition (two sample Kolmogorov-Smirnov test: $\mathrm{D}^{\wedge}{ }_{-}=0.545, p=0.0379$ ). The

441 maximum difference between the cumulative relative frequencies of PC and MC was reached

442 after two minutes $\left(\Delta_{\mathrm{PC}-\mathrm{MC}}=0.243\right)$. In the first and second minute following a conflict, the

443 probability for an affiliative contact to occur was 3.5 and 3.4, respectively, times higher than

444 without a previous conflict (Fisher's exact test: $p=0.005$ for one-minute interval; $p=0.003$ for

445 two-minute interval). This probability decreased in later time intervals. This difference was not

446 driven by extreme behaviour of single individuals (Fisher's exact test: $p=0.967)$. Following

447 Aureli et al. $(1989,42)$, we, therefore, operationally defined reconciliation as any affiliative

448 contact between the former opponents within the first two minutes subsequent to the end of their

449 conflict (Figure 3.B).

450 Applying this operational definition, 29 out of 70 aggressive interactions (41\%) could be 451 considered as reconciled. With regard to housing conditions, reconciliation occurred 5 times

452 outdoors (proportion of reconciled conflicts: 33\%) and 24 times indoors (proportion of

453 reconciled conflicts: 44\%). However, a statistical test for a housing effect on reconciliation was

454 not possible, because only three individuals provided at least three PC-MC pairs for both outdoor

455 and indoor conditions.

456 Unfortunately, for the only genuine severe aggression resulting in an injury, a reunion of the

457 opponents was impossible within $10 \mathrm{~min}$. In this case, Toba attacked Djamuna through the mesh

458 and bit her finger, whereupon Walter immediately forced Toba to copulate, which lasted about

45914 min. However, nine minutes after the aggression, Djamuna sat down near the mesh.

460 Immediately after the copulation, Toba approached the mesh, leaned towards Djamuna and

461 shaked wood wool. Within $10 \mathrm{~min}$, Djamuna held her hand towards Toba, whereupon Toba

462 gently touched the injured finger. 
464 Applying the PC/MC method for post-conflict third-party affiliative contacts resulted in 72 465 determinable PC-MC pairs, of which 29 pairs were attracted, 26 pairs were dispersed and 17 466 pairs were neutral. We calculated the proportion of attracted, dispersed and neutral PC-MC pairs 467 for each victim and conducted an exact Wilcoxon signed rank test, which revealed no 468 statistically significant difference between the proportion of attracted and dispersed PC-MC pairs $469(n=5, T=5, p=0.313)$. However, focal individuals varied with regard to their proportion of 470 attracted and dispersed PC-MC pairs. Especially Tao and Djamuna, who were the most frequent 471 victims, demonstrated opposing trends for attracted vs. dispersed PC-MC pairs: Tao 0.34 vs. 0.50 472 and Djamuna 0.43 vs. 0.22 .

473 Applying the time rule method, we found that there were more affiliative contacts in the first 474 minute of the PC $(n=25)$ than of the MC period $(n=16)$. However, the cumulative distribution 475 in the PC did not significantly differ from that in the MC (two sample Kolmogorov-Smirnov test: $476 \mathrm{D}^{\wedge}-=0.1, p=0.9048$; Figure 4). Thus, neither the PC/MC method nor the time rule method 477 demonstrated a statistically significant increase of PCTA compared to control observations. 478 However, given the small sample size and opposing trends for the two most frequently involved 479 individuals, conclusions regarding the occurrence of conflict-induced third-party affiliations in 480 this study group should be treated with caution.

481 482 483 484 485 486 487 488 489 490
Moreover, there was a difference with regard to the types of affiliative behaviour predominantly performed in the PC compared to the MC (Table 2). Contact sitting was the most frequent affiliative behaviour between victims and third parties following a conflict ( $n=24,45 \%)$, whereas it was much less frequent in the $\mathrm{MC}(n=8,15 \%)$. The probability for contact sitting to occur in PC was four times greater than in MC (Fisher's exact test on pooled data: $p=0.002$, odds ratio: 4.0). In both conditions, touch body was the second-most frequent behaviour ( $n=13$, $25 \%$ for PC, $n=14,26 \%$ for MC). Embrace, which has been indicated as a typical post-conflict third-party affiliation in chimpanzees (de Waal \& van Roosmalen, 1979), occurred more often in $\mathrm{PC}(n=6,11 \%)$ than in MC $(n=1, \%)$; however, given the small number of instances, a statistical test was not possible. 
491

492

493

494

495

496

497

498

499

500

501

502

503

504

505

506

507

508

509

510

511

512

513

514

515

516

517

518

\subsubsection{The context of male sexual coercion}

Applying the same methods in the context of male sexual coercion, only 13 PC observations were possible, particularly because several of these aggressions followed upon each other within $3 \mathrm{~min}$. The small sample size did allow neither for the application of the PC/MC method nor for the time rule method to demonstrate the occurrence of reconciliation or PCTA. However, in all cases but one, there was no affiliative contact between the former opponents within 10 min following the conflict. On the other hand, immediately after each case of forced copulation, mutual affiliative interactions took place between Toba and Eirina while still clinging at her mother, sometimes also including Tao. Thus, it seems that male sexual coercion is generally not followed by a peaceful reunion of the opponents, but by PCTA between the female and her dependent or semi-dependent offspring.

\section{Discussion}

The present study systematically investigated conflict behaviour and associated conflict resolution in a group of captive Sumatran orangutans. Overall, open conflicts occurred rarely, though increased - as expected - under less spacious conditions. In accordance with our predictions, orangutans engaged in conflict resolution, especially third-party interventions and affiliative post-conflict contacts between opponents (reconciliation).

These findings support our hypothesis that the behavioural repertoire of orangutans includes prosocial conflict resolution strategies that are similar to those of the other great apes.

\subsection{Aggressive interactions}

Although we applied a rather broad definition of aggression, the overall rate of aggressive interactions was low, which concurs with previous reports on captive orangutans (Edwards \& Snowdon, 1980; Jantschke, 1972; Poole, 1987). If a narrower definition would have been used as in previous studies on third-party intervention in captive chimpanzees (Rudolf von Rohr et al., 2012), the aggression rate might have been substantially lower.

Whereas the specific context or cause of an aggression, e.g. sexual coercion, food competition or weaning, was often obvious to the observer, the majority of aggressive interactions between females, though, seemed to occur spontaneously, without any obvious detectable reason. 
519 Nevertheless, the lack of identified causes does not justify the conclusion that there had been no

520 direct causes. Judge (2003, p. 60) suggested that many seemingly spontaneous conflicts might

521 " [...] result from violations of established patterns of social interactions that human observers

522 may not understand." For future studies, taking the relationship history of the opponents,

523 including former conflicts, into account might help to understand some "causeless" conflicts. In

524 any case, there will remain a considerable amount of uncertainty.

525 In all contexts but male sexual coercion, targets of aggression predominantly responded with

526 avoidance or non-aggressive behaviour. Forced copulations constitute a type of sexual

527 aggression absent in the African great apes, but common in both humans and orangutans (Muller,

528 Kahlenberg \& Wrangham, 2009; Muller \& Wrangham, 2009; Wrangham \& Muller, 2009). Our

529 finding that forced copulations usually provoked partially fierce aggressive responses by the

530 female is in line with observations in the wild (Utami Atmoko et al., 2009a). Moreover, the

531 extent of force by the male increased with the intensity of the female's resistance, as has been

532 reported for wild orangutans (Knott, 2009). Given the physical superiority of males due to the

533 extreme sexual dimorphism in body size (Utami Atmoko et al., 2009a), the intensity of females'

534 resistance is still puzzling.

\section{$535 \quad 4.2$ Conflict Resolution}

\section{Third-party interventions}

537 In accordance with the few published observations of third-party interventions in captive and 538 wild orangutans (Marzec et al., 2016; Tajima \& Kurotori, 2010; Zucker, 1987), the majority of

539 interventions in conflicts (except male sexual coercion) were non-aggressive and mainly

540 performed by a dominant individual. In contrast to interventions in non-sexual contexts, which

541 were all but one successful, all cases of forced copulation provoked immediate, aggressive, but

542 unsuccessful interventions by one or both of the offspring, confirming findings in wild

543 orangutans (Utami Atmoko et al., 2009a).

544 Although females seemed to intervene selectively depending on the identity of the victim,

545 suggesting the protection of the victim, helping close social partners or kin and stabilising social

546 bonds (Cords, 1997) as possible functions, there are many other potentially influential factors,

547 particularly situational ones, which have to be considered. Likewise, the two cases of peaceful 
548 intervention by the male resembled policing in other primate species (Petit \& Thierry, 2000) and

549 seem to imply a respective function, such as maintaining dominance over group members, 550 control over mating partners (Boehm, 1994; Petit \& Thierry, 2000; Watts, 1991; Watts, 1997) or 551 maintaining group stabilisation (Flack et al., 2006; Rudolf von Rohr et al., 2012). However, the

552 small number of interventions does not allow for conclusions about their functions.

\section{Reconciliation}

554 With this study, we were able to confirm the occurrence of reconciliation immediately after a 555 conflict among captive orangutans. The temporal distribution of post-conflict reunions, 556 compared to control conditions, was similar to those found for other primate species in which 557 reconciliation occurs (e.g. Aureli et al., 1993; Butovskaya \& Kozintsev, 1999; Kutsukake \& 558 Castles, 2004).

559 Several, not necessarily mutually exclusive functions for affiliative post-conflict contacts 560 between opponents are in discussion, for example: restoring valuable social relationships 561 jeopardised by the conflict (Valuable Relationship Hypothesis: Aureli et al., 1989; de Waal \& 562 Aureli, 1997), reducing uncertainty and anxiety following a conflict (Uncertainty-Reduction 563 Hypothesis: Aureli, 1997; Aureli \& van Schaik, 1991), and honestly signalling non-aggressive or 564 benign intent to enable the resumption of non-aggressive interactions (Benign Intent Hypothesis: 565 Silk, 1996; Silk, 1997; Silk, 2000).

566 Unfortunately, the generally rare occurrence of aggressive interactions, their unbalanced

567 distribution across dyads and the correspondingly small and unevenly distributed number of 568 available PC-MC pairs did not allow us to test these hypotheses. Particularly, we were not able to 569 compute the conciliatory tendency (de Waal \& Yoshihara, 1983; Veenema et al., 1994) in order 570 to draw reliable conclusions about whether the orangutans reconciled selectively with particular 571 partners. However, we consider our study as a starting point for research on conflict resolution in 572 captive orangutans. Future studies with larger samples of captive orangutan groups should 573 investigate the various proposed functions of reconciliation systematically. Moreover, it would 574 be useful to also record expressions of anxiety, such as self-directed behaviour, and to test for the 575 effect of tension reduction through reconciliation (compare e.g. Duboscq et al., 2014). 
576 Whereas we applied well-established methods to integrate our results in the large corpus of

577 reconciliation research, these methods were also conservative. Especially the operational

578 definition of reconciliation, by applying the time rule method, probably did not cover all

579 affiliative post-conflict interactions that were functionally reconciliations. Cords (1993), e.g.,

580 argued for a more functional definition of reconciliation. However, as suggested e.g. by

581 Veenema (2000), it has become common practise to combine several methods (e.g. Koski,

582 Koops \& Sterck, 2007; Mallavarapu et al., 2006; Roseth et al., 2011). It has also been pointed

583 out that species-characteristics may require an adaptation of these methods (Logan, Emery \&

584 Clayton, 2013). We want to emphasise a further aspect, which has already been recommended

585 for a different context (de Waal, Leimgruber \& Greenberg, 2008): In addition to quantitative

586 data, the qualitative description of affiliative post-conflict interactions might help to understand

587 the proximate functions of affiliations in the aftermath of a conflict.

588 Post-conflict third-party affiliations

589 In contrast to reconciliation, the temporal distribution of post-conflict third-party affiliations in

590 non-sexual contexts did not differ from that of the control observations. However, though the

591 occurrence of conflict-induced third-party affiliations with the victim could not be demonstrated

592 with the established quantitative methods, considering qualitative observational data of post-

593 conflict behaviour might provide further information (de Waal \& Aureli, 1997). Following

594 conflicts, victims and bystanders sat significantly more often in close proximity with bodily

595 contact - often combined with touching or embracing - than without previous conflict. Contact

596 sitting alongside gentle touching and embracing are typical for implicit post-conflict affiliation,

597 especially among closely bonded partners, in several species (Call, 1999; Cords, 1993; Fraser \&

598 Aureli, 2008; Verbeek, 2008). The found higher frequency of contact sitting in comparison to

599 baseline data, therefore, might hint at the occurrence of conflict-induced third-party affiliation

600 with the victim. In contrast to findings in chimpanzees (de Waal \& van Roosmalen, 1979),

601 embracing did not seem to be a typical post-conflict third-party affiliation in orangutans, at least

602 among adults. The few instances in which embracing occurred involved an immature individual.

603 However, compared to other affiliative behavioural elements, embracing occurs generally rarely

604 among adult orangutans (Liebal, Pika \& Tomasello, 2006; MacKinnon, 1974). 
605 The small number of forced copulations did not allow for a quantitative analysis of PCTA in this 606 special context. Yet, immediately subsequent to each forced copulation, Toba and one or two of 607 her daughters engaged in affiliative interactions. Here, consolation would be the most plausible 608 function (Aureli, 1997). The stress-alleviating effect of these PCTA would probably be mutual, 609 because not only the adult female, but also her daughters, especially the youngest one clinging at 610 her mother during each copulation, were affected by the aggressive interactions.

611 Furthermore, some circumstances might have potentially confounded the detection of increased 612 PCTA. First, given the small sample size, it was not possible to take the effect of different 613 contexts into account (apart from differentiating between male sexual coercion and all other 614 contexts). A considerable proportion of conflicts occurred in the context of weaning, which 615 being a regular parent-offspring conflict in primates (Maestripieri, 2002) - is not very likely to 616 affect other group members. The fact that the two individuals most frequently in the victim's role 617 demonstrated opposing trends for attracted vs. dispersed PC-MC pairs, and that one of them was 618 the semi-dependent immature involved in the weaning process, might indicate a confounding 619 context-effect. Second, not every conflict occurred in proximity to a bystander; hence, especially 620 low-level aggressions might have been not obvious to others. Third, although the individuals of 621 both subgroups had the opportunity to interact with each other through the mesh - which they 622 actually did quite often - when kept indoors, the separation potentially restricted the opportunity 623 to initiate PCTAs for bystanders and victims from different enclosures.

624 As for reconciliations, the main objective of this study was to investigate whether conflicts 625 provoke post-conflict affiliations in captive orangutans. In the case of PCTAs, this investigation 626 did not lead to clearly positive results. Therefore, a meaningful discussion of probable functions 627 of PCTA in orangutans is not possible at this point.

\section{$628 \quad 4.3$ Coping with crowded conditions}

629 With respect to the two housing conditions, aggressions increased in both frequency and 630 intensity under less spacious conditions. Simultaneously and in accordance to our predictions, 631 the probability of third-party interventions increased indoors. Additionally, data of the same 632 study group regarding food sharing demonstrated an increase in the proportion of food sharing 633 among adult orangutan females when kept indoors (Kopp, 2017). These findings are in line with 
634 those of a study investigating the effect of differing housing conditions on the social behaviour 635 of captive chimpanzees (Nieuwenhuijsen \& de Waal, 1982). Here, the aggression rate increased 636 indoors as did the rate of affiliative interactions. The authors interpreted this finding as a coping 637 strategy for medium-term crowding (see also Caperos et al., 2011; Judge, 2000; Judge \& de 638 Waal, 1997). Moreover, whereas Nieuwenhuijsen and de Waal (1982) focused on affiliative 639 behaviour in general, we specifically investigated prosocial behaviours directly associated with 640 aggressive interactions. Therefore, the finding that bystanders ceased conflicts more likely under 641 crowded conditions suggests that socially housed orangutans not only reduce social tension by 642 affiliative interactions, but also flexibly use prosocial conflict resolution strategies when 643 dispersion is not possible.

644 On the other hand, our results seem to be contrary to those of Aureli and de Waal (1997), who 645 found a general decrease of both affiliative and agonistic behaviour in adult chimpanzees under 646 crowded conditions. However, the situations of the chimpanzees and the orangutans in both 647 studies differed substantially: Whereas the chimpanzees were locked up in their indoor 648 enclosures no longer than for five consecutive days, the orangutans had already been kept 649 indoors for about three months when we started our indoor observations. Moreover, the mean 650 density was about ten times higher for the chimpanzees than for the orangutans in the current 651 study. Following the authors' interpretation of the general decrease in social behaviour as a 652 short-term response to extremely high density (Aureli \& de Waal, 1997), the obvious differences 653 to our results and those of the study by Nieuwenhuijsen and de Waal (1982) seem to indicate 654 different strategies to cope with varying levels of social density.

655 Several conflicts in the indoor enclosure occurred through the mesh that separated the two 656 subgroups. The mesh potentially provided the opportunity to attack an individual of the other 657 subgroup and escape an immediate retribution by withdrawing from their reach. We cannot rule 658 out that - in particular lower ranking - individuals might have been encouraged by this 659 opportunity, but we found no evidence for a general increasing effect on the probability of 660 aggression. 


\section{Conclusion and future directions}

662 With the present study on socially housed Sumatran orangutans, we demonstrate that the

663 behavioural repertoire of orangutans includes a potential of conflict resolution even though this

664 is barely needed under natural conditions.

665 Whereas avoidance is the predominant strategy for free-ranging orangutans to prevent conflicts, 666 orangutans are capable to cease ongoing conflicts by third-party intervention and tend to 667 reconcile after conflicts when living in permanent groups.

668 Taken into account the phylogenetic proximity of orangutans, gorillas, bonobos, chimpanzees 669 and humans and the similarity of the respective conflict resolution strategies across these species, 670 our findings support the hypothesis that prosocial conflict resolution is a common evolutionary 671 heritage of all extant hominids.

672 In view of the dramatic loss of orangutan habitat and the increasing number of orangutans living 673 in rescue centres, their potential to solve conflicts may become increasingly important. Future 674 research is needed to increase our still very restricted knowledge about their abilities of conflict 675 resolution and its functions as well as about influencing social and contextual factors. A better 676 understanding of these crucial aspects of social life may also improve the welfare of orangutans 677 in rescue centres and zoos due to husbandry conditions adjusted to the needs of group-living 678 orangutans.

\section{Acknowledgements}

680 We cordially thank the directorate and keepers at Zoo Dortmund for allowing us to conduct this 681 study and their constant support in collecting the data, especially Ilona Schappert, Eddy Laudert, 682 Natascha Kurt, Sonja Borchers and Jörg Woitzik. Special thanks go to Martin Schultze for 683 statistical advice and to Paula Sophia Mahlke for conducting the reliability coding. Finally, we 684 thank Jennifer Vonk as the academic editor, and Frans de Waal, Christine Webb and an 685 anonymous reviewer for very helpful comments on earlier versions of the manuscript. 
686

687

688

689

690

691

692

693

694

695

696

697

698

699

700

701

702

703

704

705

706

707

708

709

710

711

712

713

714

715

716

717

718

719

720

721

722

723

724

725

726

727

728

729

\section{References}

Altmann J. 1974. Observational study of behavior: sampling methods. Behaviour 49:227-267. $10.1163 / 156853974 X 00534$

Arora N, van Noordwijk MA, Ackermann C, Willems EP, Nater A, Greminger M, Nietlisbach P, Dunkel LP, Utami Atmoko SS, Pamungkas J. 2012. Parentage-based pedigree reconstruction reveals female matrilineal clusters and male-biased dispersal in nongregarious Asian great apes, the Bornean orang-utans (Pongo pygmaeus). Molecular ecology 21:3352-3362. 10.1111/j.1365-294X.2012.05608.x

Aureli F. 1997. Post-conflict anxiety in nonhuman primates: the mediating role of emotion in conflict resolution. Aggressive Behavior 23:315-328. 10.1002/(SICI)10982337(1997)23:5<315::AID-AB2>3.0.CO;2-H

Aureli F, Cords M, van Schaik CP. 2002. Conflict resolution following aggression in gregarious animals: a predictive framework. Anim Behav 64:325-343. 10.1006/anbe.2002.3071

Aureli F, de Waal FBM. 1997. Inhibition of social behavior in chimpanzees under high-density conditions. Am J Primatol 41:213-228. 10.1002/(SICI)1098-2345(1997)41:3<213::AIDAJP4>3.0.CO;2-\#

Aureli F, de Waal FBM. 2000a. Natural Conflict Resolution. Berkeley, Los Angeles, California: University of California Press.

Aureli F, de Waal FBM. 2000b. Why natural conflict resolution? In: Aureli F, de Waal FBM, eds. Natural Conflict Resolution. Berkeley, CA, US: University of California Press, 3-10.

Aureli F, Schaffner CM, Boesch C, Bearder SK, Call J, Chapman CA, Connor R, Di Fiore A, Dunbar RIM, Henzi SP, Holekamp K, Korstjens AH, Layton R, Lee P, Lehmann J, Manson JH, Ramos-Fernandez G, Strier KB, van Schaik CP. 2008. Fission-fusion dynamics: new research frameworks. Current Anthroplogy 49:627-654. 10.1086/586708

Aureli F, van Schaik CP. 1991. Post-conflict behavior in long-tailed macaques (Macaca fascicularis): I. The social events. Ethology 89:89-100. 10.1111/j.14390310.1991.tb00296.x

Aureli F, van Schaik CP, van Hooff JARAM. 1989. Functional aspects of reconciliation among captive long-tailed macaques (Macaca fascicularis). Am J Primatol 19:39-51. 10.1002/ajp.1350190105

Aureli F, Veenema HC, van Panthaleon van Eck CJ, van Hooff JARAM. 1993. Reconciliation, consolation, and redirection in Japanese macaques (Macaca fuscata). BEHAVIOUR 124:1-21. 10.1163/156853993X00470

Boehm C. 1994. Pacifying interventions at Arnhem Zoo and Gombe. In: Wrangham RW, McGrew WC, de Waal FBM, Heltne PG, eds. Chimpanzee Cultures. Cambridge: Harvard University Press, 211-226.

Boesch C. 1994. Cooperative hunting in wild chimpanzees. Anim Behav 48:653-667. 10.1006/anbe.1994.1285

Butovskaya M, Kozintsev A. 1999. Aggression, friendship, and reconciliation in Russian primary schoolchildren. Aggressive Behavior 25:125-139. 10.1002/(SICI)10982337(1999)25:2<125::AID-AB5>3.0.CO;2-X

Call J. 1999. The effect of inter-opponent distance on the occurrence of reconciliation in stumptail (Macaca arctoides) and rhesus macaques (Macaca mulatta). Primates 40:515523. 10.1007/BF02557587 
730

731

732

733

734

735

736

737

738

739

740

741

742

743

744

745

746

747

748

749

750

751

752

753

754

755

756

757

758

759

760

761

762

763

764

765

766

767

768

769

770

771

772

773

774

775

Caperos JM, Sánchez S, Peláez F, Fidalgo A, Morcillo A. 2011. The effect of crowding on the social behavior of the cooperatively breeding cotton-top tamarins (Saguinus oedipus). International Journal of Primatology 32:1179-1189. 10.1007/s10764-011-9534-7

Cordoni G, Palagi E, Borgognini Tarli S. 2006. Reconciliation and consolation in captive western gorillas. International Journal of Primatology 27:1365-1382. 10.1007/s10764006-9078-4

Cords M. 1993. On operationally defining reconciliation. Am J Primatol 29:255-267. 10.1002/ajp.1350290403

Cords M. 1997. Friendships, alliances, reciprocity and repair. In: Whiten A, Byrne RW, eds. Machiavellian intelligence II. Cambridge: Cambridge University Press, 29-49.

Cords M, Killen M. 1998. Conflict resolution in human and nonhuman primates. In: Langer J, Killen M, eds. Piaget, Evolution, and Development. Mahwah, NJ, US: Lawrence Erlbaum Associates Publishers, 193-218.

Csardi G, Nepusz T. 2006. The igraph software package for complex network research. InterJournal Complex Systems:1695.

de Waal FBM, Aureli F. 1997. Conflict resolution and distress alleviation in monkeys and apes. Integrative Neurobiology of Affiliation 807:317-328. 10.1111/j.17496632.1997.tb51929.x

de Waal FBM, Leimgruber K, Greenberg AR. 2008. Giving is self-rewarding for monkeys. Proc Natl Acad Sci U S A 105:13685-13689. 10.1073/pnas.0807060105

de Waal FBM, van Roosmalen A. 1979. Reconciliation and consolation among chimpanzees. Behavioural Ecology and Sociobiology 5:55-66. 10.1007/BF00302695

de Waal FBM, Yoshihara D. 1983. Reconciliation and redirected affection in rhesus monkeys. BEHAVIOUR 85:224-241. 10.1163/156853983X00237

Delgado RA, Jr., van Schaik CP. 2000. The behavioral ecology and conservation of the orangutan (Pongo pygmaeus): a tale of two islands. Evolutionary Anthropology 9:201218. 10.1002/1520-6505(2000)9:5<201::AID-EVAN2>3.0.CO;2-Y

Duboscq J, Agil M, Engelhardt A, Thierry B. 2014. The function of postconflict interactions: New prospects from the study of a tolerant species of primate. Animal Behaviour 87:107120. 10.1016/j.anbehav.2013.10.018

Edwards SD, Snowdon CT. 1980. Social behavior of captive, group-living orang-utans. International Journal of Primatology 1:39-62. 10.1007/BF02692257

Flack JC, Girvan M, de Waal FBM, Krakauer DC. 2006. Policing stabilizes construction of social niches in primates. Nature 439. 10.1038/nature04326

Fox J, Weisberg S. 2011. An $\{\mathrm{R}\}$ companion to applied regression. Second ed. Thousand Oaks CA: Sage.

Fraser ON, Aureli F. 2008. Reconciliation, consolation and postconflict behavioral specificity in chimpanzees. Am J Primatol 70:1114-1123. 10.1002/ajp.20608

Fraser ON, Stahl D, Aureli F. 2008. Stress reduction through consolation in chimpanzees. Proc Natl Acad Sci U S A 105:8557-8562. 10.1073/pnas.0804141105

Furuichi T, Ihobe H. 1994. Variation in male relationships in bonobos and chimpanzees. BEHAVIOUR 130:211-228. 10.1163/156853994X00532

Gamer M, Lemon J, Fellows I, Puspendra S. 2012. irr: various coefficients to interrater reliability and agreement. $\mathrm{R}$ package $0.84 \mathrm{ed}$.

Hothorn T, Hornik K. 2015. exactRankTests: exact distributions for rank and permutation tests. R package $0.8-28$ ed. 
776

777

778

779

780

781

782

783

784

785

786

787

788

789

790

791

792

793

794

795

796

797

798

799

800

801

802

803

804

805

806

807

808

809

810

811

812

813

814

815

816

817

818

819

820

Husson SJ, Wich SA, Marshall AJ, Dennis RD, Ancrenaz M, Brassey R, Gumal M, Hearn AJ, Meijaard E, Simorangkir T. 2009. Orangutan distribution, density, abundance and impacts of disturbance. In: Wich SA, Utami Atmoko SS, Mitra Setia T, van Schaik CP, eds. Orangutans: Geographic Variation in Behavioral Ecology and Conservation. New York: Oxford University Press, 77-96.

Jaeggi AV, de Groot E, Stevens JMG, van Schaik CP. 2013. Mechanisms of reciprocity in primates: testing for short-term contingency of grooming and food sharing in bonobos and chimpanzees. Evolution and Human Behavior 34:69-77. 10.1016/j.evolhumbehav.2012.09.005

Janson CH. 1988. Intra-specific food competition and primate social structure: a synthesis. BEHAVIOUR 105:1-17. 10.1163/156853988X00412

Jantschke F. 1972. Orang-Utans in Zoologischen Gärten. München: R. Piper \& Co. Verlag.

Judge PG. 2000. Coping with crowded conditions. In: Aureli F, de Waal FBM, eds. Natural Conflict Resolution. Berkeley, CA, US: University of California Press, 129-154.

Judge PG. 2003. Conflict resolution. In: Maestripieri D, ed. Primate Psychology. Cambridge, MA, US: Harvard University Press, 41-68.

Judge PG, de Waal FBM. 1997. Rhesus monkey behaviour under diverse population densities: coping with long-term crowding. Anim Behav 54:643-662. 10.1006/anbe.1997.0469

Knott CD. 2009. Orangutans: Sexual coercion without sexual violence. In: Muller MN, Wrangham RW, eds. Sexual Coercion in Primates and Humans An Evolutionary Perspective on Male Aggression Against Females. Boston: Harvard University Press, 81111.

Kopp KS. 2017. Prosocial Behaviour in Captive Sumatran Orangutans (Pongo abelii) Dr. phil. Doctoral Thesis. Freie Universität Berlin. Available at http://www.diss.fuberlin.de/diss/receive/FUDISS thesis 000000104317

Kopp KS, Liebal K. 2016. Here you are!-Selective and active food sharing within and between groups in captive Sumatran orangutans (Pongo abelii). Behavioral Ecology and Sociobiology 70:1219-1233. 10.1007/s00265-016-2130-2

Koski SE, Koops K, Sterck EHM. 2007. Reconciliation, relationship quality, and postconflict anxiety: Testing the integrated hypothesis in captive chimpanzees. Am J Primatol 69:158172. 10.1002/ajp.20338

Kummer H. 1978. On the value of social relationships in nonhuman primates: A heuristic scheme. Social Science Information 17:687-705. 10.1177/053901847801700418

Kutsukake N, Castles DL. 2004. Reconciliation and post-conflict third-party affiliation among wild chimpanzees in the Mahale Mountains, Tanzania. Primates 45:157-165. 10.1007/s10329-004-0082-z

Langergraber K, Mitani J, Vigilant L. 2009. Kinship and social bonds in female chimpanzees (Pan troglodytes). Am J Primatol 71:840-851. 10.1002/ajp.20711

Liebal K, Pika S, Tomasello M. 2006. Gestural communication of orangutans (Pongo pygmaeus). Gesture 6:1-38. 10.1075/gest.6.1.02lie

Liebal K, Rossano F. 2017. The give and take of food sharing in Sumatran orang-utans, Pongo abelii, and chimpanzees, Pan troglodytes. Anim Behav 133:91-100. 10.1016/j.anbehav.2017.09.006

Logan CJ, Emery NJ, Clayton NS. 2013. Alternative behavioral measures of postconflict affiliation. Behavioral Ecology 24:98-112. 10.1093/beheco/ars140 
821

822

823

824

825

826

827

828

829

830

831

832

833

834

835

836

837

838

839

840

841

842

843

844

845

846

847

848

849

850

851

852

853

854

855

856

857

858

859

860

861

862

863

864

865

866

MacKinnon J. 1974. The behaviour and ecology of wild orang-utans (Pongo pygmaeus). Anim Behav 22:3-74. 10.1016/S0003-3472(74)80054-0

Maechler M, Stahel W, Ruckstuhl A, Keller C, Halvorsen K, Hauser A, Buser C, Gygax L, Venables B, Plate T, Flückiger I, Wolbers M, Keller M, Dudoit S, Fridlyand J, Snow G, Nielsen HA, Carey V, Bolker B, Grosjean P, Ibanez F, Savi C, Geyer C, Oehlschlägel J. 2016. sfsmisc: Utilities from "Seminar fuer Statistik" ETH Zurich. R package version $1.1-0$ ed.

Maestripieri D. 2002. Parent-offspring conflict in primates. International Journal of Primatology 23:923-951. 10.1023/A:1015537201184

Mallavarapu S, Stoinski TS, Bloomsmith MA, Maple TL. 2006. Postconflict behavior in captive western lowland gorillas (Gorilla gorilla gorilla). Am J Primatol 68:789-801. 10.1002/ajp.20279

Marzec AM, Kunz JA, Falkner S, Atmoko SSU, Alavi SE, Moldawer AM, Vogel ER, Schuppli C, van Schaik CP, van Noordwijk MA. 2016. The dark side of the red ape: malemediated lethal female competition in Bornean orangutans. Behavioral Ecology and Sociobiology 70:459-466. 10.1007/s00265-015-2053-3

Mitani JC. 2009. Male chimpanzees form enduring and equitable social bonds. Anim Behav 77:633-640. 10.1016/j.anbehav.2008.11.021

Mitra Setia T, Delgado RA, Utami Atmoko SS, Singleton I, van Schaik CP. 2009. Social organization and male-female relationships. In: Wich SA, Utami Atmoko SS, Mitra Setia T, van Schaik CP, eds. Orangutans: Geographic Variation in Behavioral Ecology and Conservation. New York: Oxford University Press, 245-253.

Muller MN, Kahlenberg SM, Wrangham RW. 2009. Male Aggression and Sexual Coercion of Females in Primates. In: Muller Martin N, Wrangham Richard W, eds. Sexual Coercion in Primates and Humans An Evolutionary Perspective on Male Aggression Against Females. Boston: Harvard University Press, 3-22.

Muller MN, Wrangham RW. 2009. Sexual Coercion in Primates and Humans, An Evolutionary Perspective on Male Aggression Against Females. Boston: Harvard University Press.

Nellemann C, Miles L, Kaltenborn BP, Virtue M, Ahlenius H. 2007. The last stand of the orangutan - State of emergency: Illegal logging, fire and palm oil in Indonesia's national parks.: United Nations Environment Programme. GRID-Arendal, Norway.

Nieuwenhuijsen K, de Waal FBM. 1982. Effects of spatial crowding on social behavior in a chimpanzee colony. Zoo Biol 1:5-28. 10.1002/zoo.1430010103

Opsahl T. 2009. Structure and Evolution of Weighted Networks. University of London (Queen Mary College). Available at http://toreopsahl.com/publications/thesis/

Palagi E, Norscia I. 2013. Bonobos protect and console friends and kin. PLoS One 8. 10.1371/journal.pone.0079290

Palagi E, Paoli T, Borgognini Tarli S. 2004. Reconciliation and consolation in captive bonobos (Pan paniscus). Am J Primatol 62:15-30. 10.1002/ajp.20000

Parnell RJ. 2002. Group size and structure in western lowland gorillas (Gorilla gorilla gorilla) at Mbeli Bai, Republic of Congo. Am J Primatol 56:193-206.

Petit O, Thierry B. 2000. Do impartial interventions in conflicts occur in monkeys and apes? In: Aureli F, de Waal FBM, eds. Natural Conflict Resolution. Berkeley, CA, US: University of California Press, 267-269, Box 213.261.

Poole TB. 1987. Social behavior of a group of orangutans (Pongo pygmaeus) on an artificial island in Singapore Zoological Gardens. Zoo Biol 6:315-330. 10.1002/zoo.1430060406

PeerJ reviewing PDF | (2018:02:24322:2:0:NEW 28 Jun 2018) 
867 R Core Team. 2017. R: A language and environment for statistical computing. Vienna, Austria:

868

869

870

871

872

873

874

875

876

877

878

879

880

881

882

883

884

885

886

887

888

889

890

891

892

893

894

895

896

897

898

899

900

901

902

903

904

905

906

907

908

909

910

911

912 R Foundation for Statistical Computing.

Robbins MM. 1995. A Demographic Analysis of Male Life History and Social Structure of Mountain Gorillas. BEHAVIOUR 132:21-47. 10.1163/156853995X00261

Robbins MM. 2008. Feeding competition and agonistic relationships among Bwindi Gorilla beringei. International Journal of Primatology 29:999-1018. 10.1007/s10764-008-92754

Romero T, de Waal FBM. 2010. Chimpanzee (Pan troglodytes) consolation: third-party identity as a window on possible function. JOURNAL OF COMPARATIVE PSYCHOLOGY 124:278-286. 10.1037/a0019144

Roseth CJ, Pellegrini AD, Dupuis DN, Bohn CM, Hickey MC, Hilk CL, Peshkam A. 2011. Preschoolers' bistrategic resource control, reconciliation, and peer regard. Social Development 20:185-211. 10.1111/j.1467-9507.2010.00579.x

Rudolf von Rohr C, Koski SE, Burkart JM, Caws C, Fraser ON, Ziltener A, van Schaik CP. 2012. Impartial third-party interventions in captive chimpanzees: A reflection of community concern. PLoS One 7. 10.1371/journal.pone.0032494

Russon AE. 2009. Orangutan rehabilitation and reintroduction. Successes, failures, and role in conservation. In: Wich SA, Utami Atmoko SS, Mitra Setia T, van Schaik CP, eds. Orangutans: Geographic Variation in Behavioral Ecology and Conservation. New York: Oxford University Press, 327-350.

Scott J, Lockard JS. 2007. Competition coalitions and conflict interventions among captive female gorillas. International Journal of Primatology 28:761-781. 10.1007/s10764-0079161-5

Seyfarth RM, Cheney DL. 2012. The evolutionary origins of friendship. In: Fiske ST, Schacter DL, Taylor SE, eds. Annual Review of Psychology, 153-177.

Silk JB. 1996. Why do primates reconcile? Evolutionary Anthropology 5:39-42. 10.1002/(SICI)1520-6505(1996)5:2<39::AID-EVAN2>3.0.CO;2-R

Silk JB. 1997. The function of peaceful post-conflict contacts among primates. Primates 38:265279. 10.1007/BF02381614

Silk JB. 2000. The function of peaceful post-conflict interactions. An alternative view. In: Aureli F, de Waal FBM, eds. Natural Conflict Resolution. Berkeley, CA, US: University of California Press, 179-181, Box 179.171.

Silk JB. 2002. The form and function of reconciliation in primates. Annual Review of Anthropology 31:21-44. 10.1146/annurev.anthro.31.032902.101743

Singleton I, Knott CD, Morrogh-Bernard HC, Wich SA, van Schaik CP. 2009. Ranging behavior of orangutan females and social organization. In: Wich SA, Utami-Atmoko SS, Setia TM, van Schaik CP, eds. Orangutans: Geographic Variation in Behavioral Ecology and Conservation. New York: Oxford University Press, 205-213.

Singleton I, van Schaik CP. 2002. The social organisation of a population of Sumatran orangutans. Folia Primatologica 73:1-20. 10.1159/000060415

Tajima T, Kurotori H. 2010. Nonaggressive interventions by third parties in conflicts among captive Bornean orangutans (Pongo pygmaeus). Primates 51:179-182. 10.1007/s10329009-0180-z

Utami Atmoko SS, Mitra Setia T, Goossens B, James SS, Knott CD, Morrogh-Bernard HC, van Schaik CP, van Noordwijk MA. 2009a. Orangutan mating behavior and strategies. In: Wich SA, Utami Atmoko SS, Mitra Setia T, van Schaik CP, eds. Orangutans: 
913

914

915

916

917

918

919

920

921

922

923

924

925

926

927

928

929

930

931

932

933

934

935

936

937

938

939

940

941

942

943

944

945

946

947

948

949

950

951

952

953

954

955

956

957

958

Geographic Variation in Behavioral Ecology and Conservation. New York: Oxford University Press, 235-244.

Utami Atmoko SS, Singleton I, van Noordwijk MA, van Schaik CP, Mitra Setia T. 2009b. Male-male relationships in orangutans. In: Wich SA, Utami-Atmoko SS, Setia TM, van Schaik CP, eds. Orangutans: Geographic Variation in Behavioral Ecology and Conservation: Oxford University Press, 225-234.

van Noordwijk MA, Arora N, Willems EP, Dunkel LP, Amda RN, Mardianah N, Ackermann C, Krützen M, van Schaik CP. 2012. Female philopatry and its social benefits among Bornean orangutans. Behavioral Ecology and Sociobiology 66:823-834. 10.1007/s00265012-1330-7

van Noordwijk MA, van Schaik CP. 2005. Development of ecological competence in Sumatran orangutans. Am J Phys Anthropol 127:79-94. 10.1002/ajpa.10426

van Schaik CP. 1999. The socioecology of fission-fusion sociality in orangutans. Primates 40:69-86. 10.1007/BF02557703

van Schaik CP, Marshall AJ, Wich SA. 2009. Geographic variation in orangutan behavior and biology. Its functional interpretations and its mechanistic basis. In: Wich SA, Utami Atmoko SS, Mitra Setia T, van Schaik CP, eds. Orangutans: Geographic Variation in Behavioral Ecology and Conservation. New York: Oxford University Press, 351-361.

Veenema HC. 2000. Methodological progress in post-conflict research. In: Aureli F, de Waal FBM, eds. Natural Conflict Resolution. Berkeley, CA, US: University of California Press, 21-23, Box 22.21.

Veenema HC, Das M, Aureli F. 1994. Methodological improvements for the study of reconciliation. Behav Processes 31:29-37. 10.1016/0376-6357(94)90035-3

Verbeek P. 2008. Peace ethology. Behaviour 145:1497-1524. 10.1163/156853908786131270

Watts DP. 1991. Harassment of immigrant female mountain gorillas by resident females. Ethology 89:135-153. 10.1111/j.1439-0310.1991.tb00300.x

Watts DP. 1995a. Post-conflict social events in wild mountain gorillas (Mammalia, Hominoidea). I. Social interactions between opponents. Ethology 100:139-157. 10.1111/j.1439-0310.1995.tb00321.x

Watts DP. 1995b. Post-conflict social events in wild mountain gorillas. II. Redirection, side direction, and consolation. Ethology 100:158-174. 10.1111/j.1439-0310.1995.tb00322.x

Watts DP. 1997. Agonistic interventions in wild mountain gorilla groups. BEHAVIOUR 134:2357. 10.1163/156853997X00269

Wittig RM, Crockford C, Wilkberg E, Seyfarth RM, Cheney DL. 2007. Kin-mediated reconciliation substitutes for direct reconciliation in female baboons. Proceedings of the Royal Society B: Biological Sciences 274:1109-1115. 10.1098/rspb.2006.0203

Wrangham RW, Muller MN. 2009. Sexual coercion in humans and other primates: The road ahead. In: Muller MN, Wrangham RW, eds. Sexual Coercion in Primates and Humans An Evolutionary Perspective on Male Aggression Against Females. Boston: Harvard University Press, 451-468.

Zucker EL. 1987. Control of intragroup aggression by a captive male orangutan. Zoo Biol 6:219223. 10.1002/zoo.1430060304

Zucker EL, Dennon MB, Puleo SG, Maple TL. 1986. Play profiles of captive adult orangutans: a developmental perspective. Dev Psychobiol 19:315-326. 10.1002/dev.420190404

Zucker EL, Mitchell G, Maple TL. 1978. Adult male-offspring play interactions within a captive group of orang-utans (Pongo pygmaeus). Primates 19:379-384. 10.1007/BF02382806 


\section{Figure 1}

Aggressive interactions for directed dyads differentiated with regard to the respective housing condition.

(A) outdoor-enclosure: all individuals were grouped together, (B) indoor-enclosures: individuals were kept in two subgroups in neighbouring enclosures (indicated by different colours) with the opportunity to interact through the separating mesh (indicated by a vertical dashed line). Vertices (circles) indicate the particular individuals with their size corresponding to the absolute number of conflicts in which the particular individual was involved as aggressor. Edges (connecting lines) indicate aggressive interactions with their size corresponding to the absolute number for the particular aggressor-victim-dyad; arrows indicate the direction of the aggression.
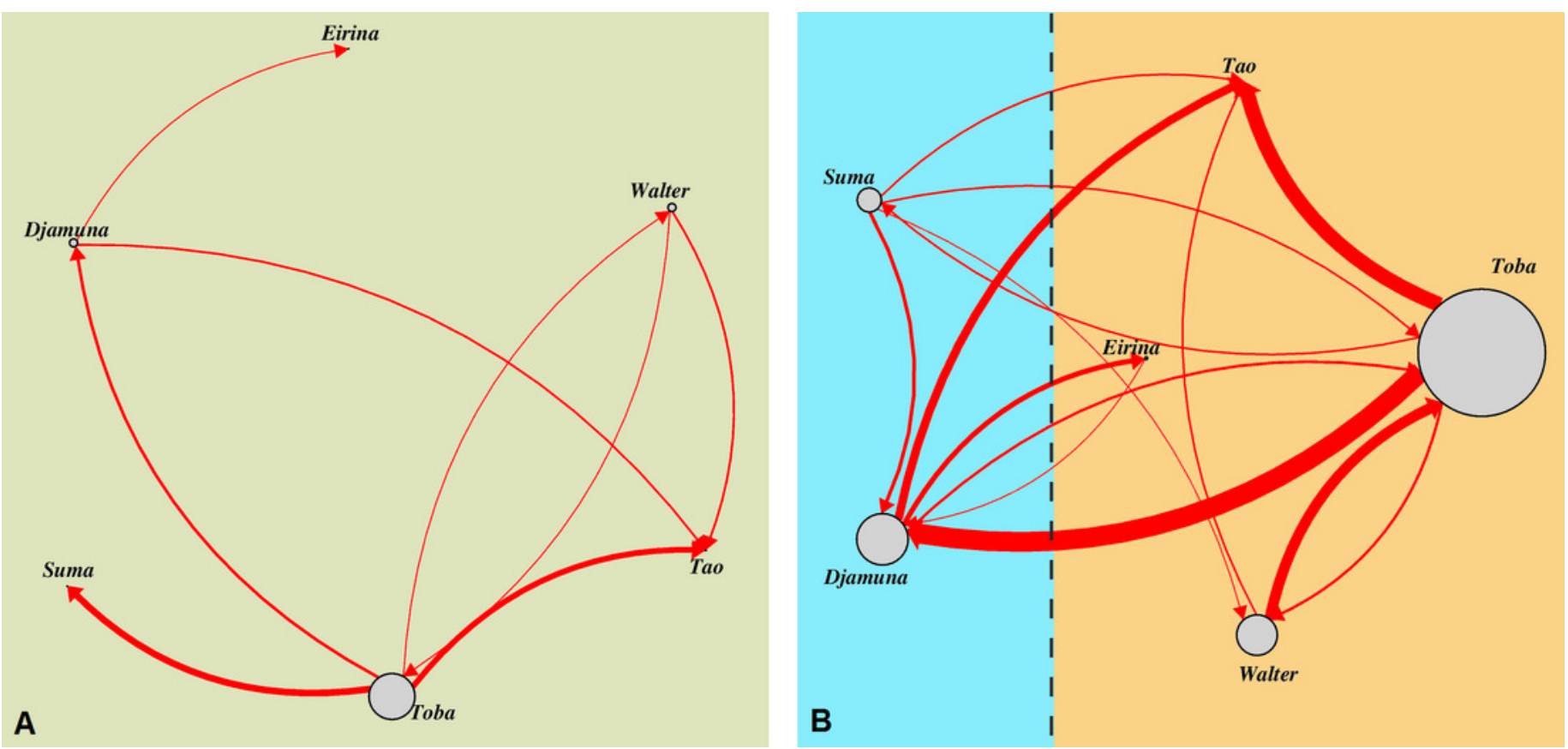


\section{Figure 2}

Proportion of attracted, dispersed and neutral PC-MC pairs across focal individuals (victims)

Each coloured symbol indicates a particular individual. Boxplots summarise these data for attracted, dispersed and neutral PC-MC pairs with horizontal lines indicating medians, boxes indicating interquartile ranges and whiskers indicating minima and maxima. Coloured lines connect data points of attracted and dispersed PC-MC pairs for each focal individual. Numbers in brackets following the individuals' names indicate the absolute frequency of PCMC pairs for each focal individual. Statistical significance at the $\alpha$-level of 0.05 is indicated by an asterisk above the curly bracket.

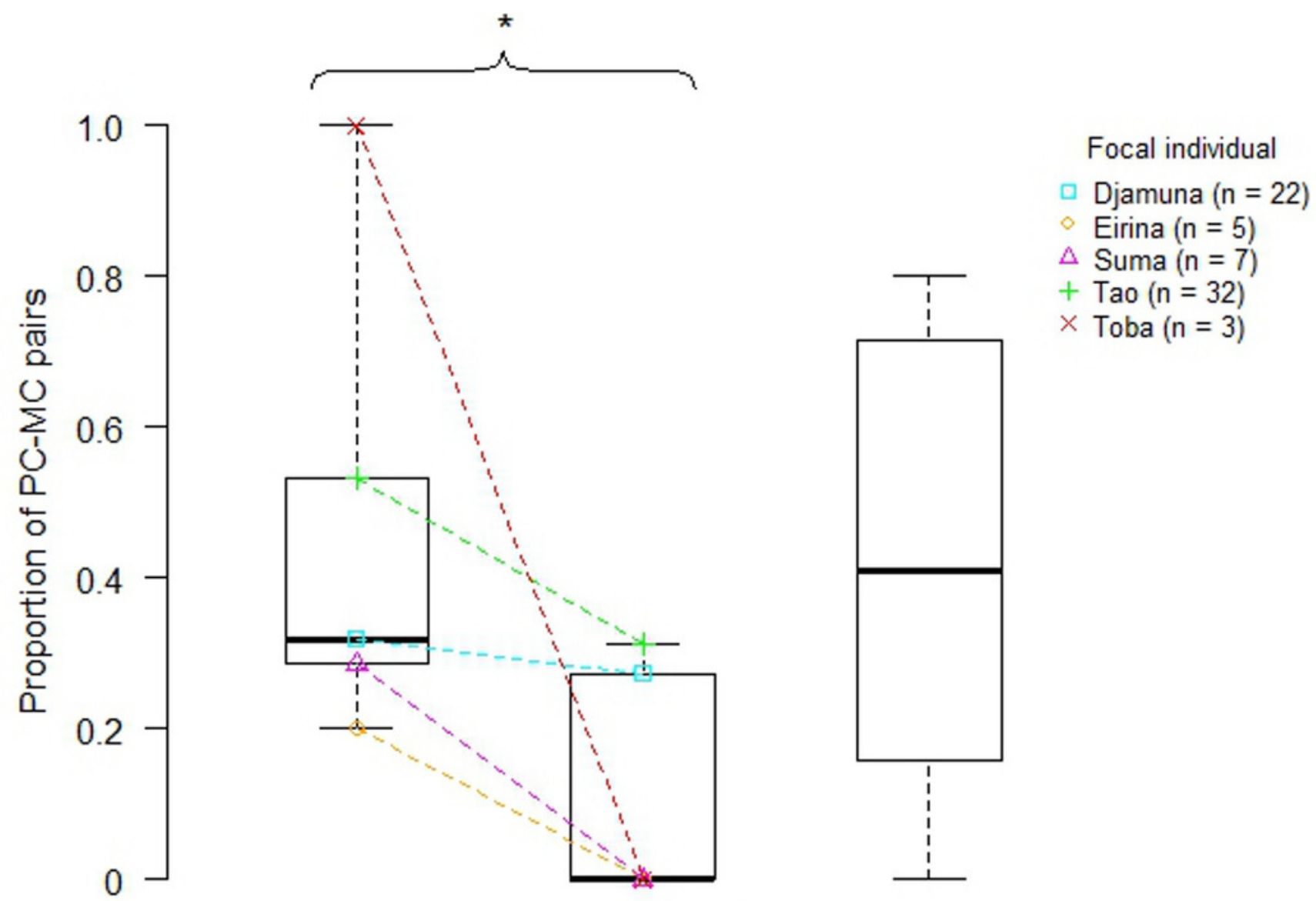

Attracted Dispersed Neutral 


\section{Figure 3}

Absolute frequencies and cumulative distribution over time (10 $\mathrm{min}$ ) of first affiliative contacts between opponents in PC and MC conditions.

(A) demonstrates the number of affiliative contacts per one-minute time interval.(B) demonstrates the cumulated relative frequencies over time, measured in one-minute time intervals. PC observations are indicated by red, MC observations by blue lines. The bracket in graph (B) indicates the time window in which each affiliative contact between opponents can be regarded as reconciliation (Aureli et al. 1989).

\section{First affiliative contacts between opponents}
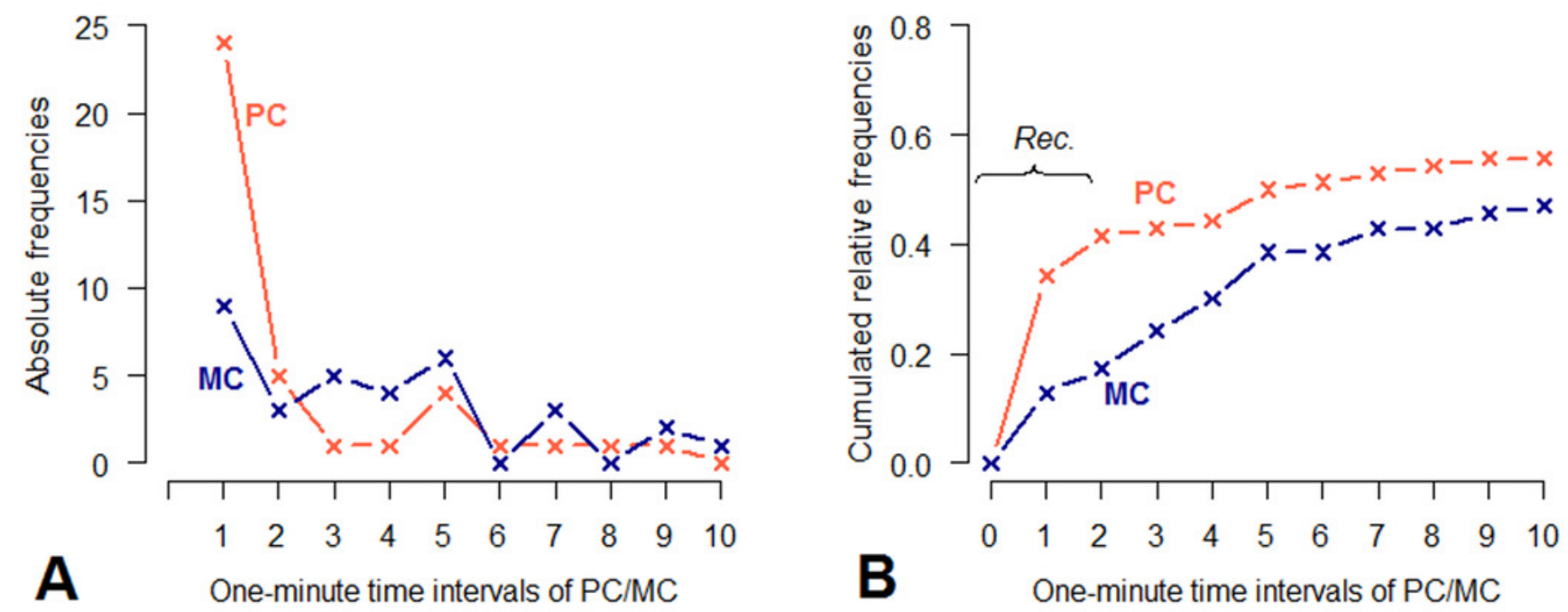


\section{Figure 4}

Absolute frequencies and cumulative distribution over time (10 $\mathrm{min}$ ) of first affiliative contacts between victims and third parties in PC and MC conditions.

(A) demonstrates the number of affiliative contacts per one-minute time interval.(B) demonstrates the cumulated relative frequencies over time, measured in one-minute time intervals. PC observations are indicated by red, MC observations by blue lines.

First affiliative contacts between victims and third parties
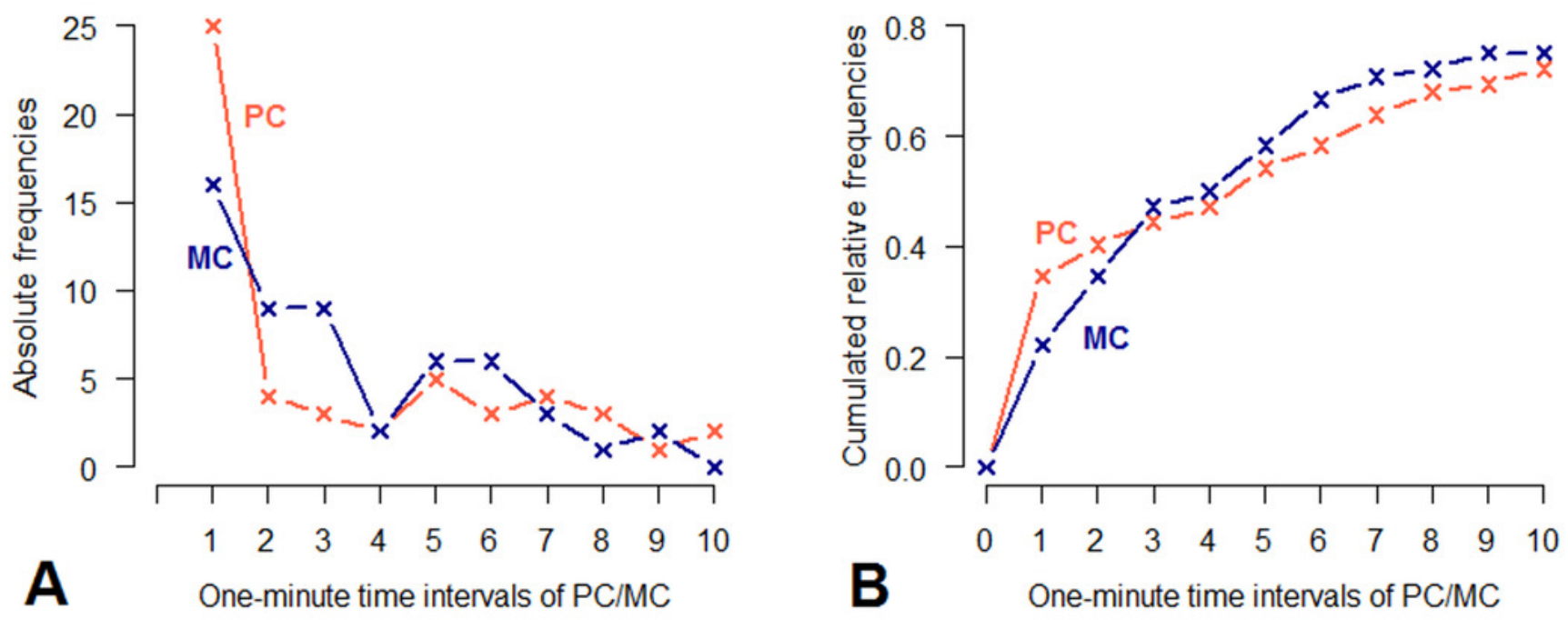


\section{Table $\mathbf{1}$ (on next page)}

Details of observed individuals: sex, age and kin relation with other group members.

Age categories have been assigned following van Noordwijk \& van Schaik (2005). A and B, resp., refer to the subgroups formed during the winter. 


\begin{tabular}{llllll}
\hline Individual & Sex & Date of birth & Age category & Subgroup & Kinship \\
\hline Walter (Wa) & male & $24 / 04 / 1989$ & adult & A & father of Ta and Ei \\
Toba $(\mathrm{To})$ & female & $07 / 02 / 1994$ & adult & A & mother of Ta and Ei \\
Tao $(\mathrm{Ta})$ & female & $18 / 11 / 2004$ & semi-dependent immature & A & daughter of Wa and To \\
Eirina (Ei) & female & $30 / 12 / 2007$ & dependent immature & A & daughter of Wa and To \\
Suma (Su) & female & $14 / 03 / 1993$ & adult & B & no kin \\
Djamuna (Dm) & female & $28 / 05 / 1999$ & adult & B & no kin \\
\hline
\end{tabular}

1 


\section{Table 2 (on next page)}

Absolute and relative frequencies of affiliative behaviours observed between victims and third parties during PC and MC, resp.

Red boxes indicate the most frequent behaviour for each condition. Proportions refer to the total number of affiliative contacts ( $n=53$ for PC, $n=54$ for MC), they do not sum to $100 \%$ since several affiliative contacts were combinations of two behaviours. 


\begin{tabular}{lllll}
\hline Affiliative Behaviour & \multicolumn{2}{l}{ PC victim/third party } & \multicolumn{2}{l}{ MC victim/third party } \\
& number & proportion & number & proportion \\
\hline Contact sitting & 24 & $45 \%$ & 8 & $15 \%$ \\
Touch body & 13 & $25 \%$ & 14 & $26 \%$ \\
Embrace & 6 & $11 \%$ & 2 & $4 \%$ \\
Play & 6 & $11 \%$ & 23 & $43 \%$ \\
Food/object transfer & 4 & $8 \%$ & 3 & $6 \%$ \\
Sucking at fur/offer fur & 3 & $6 \%$ & 7 & $13 \%$ \\
Nursing & 2 & $4 \%$ & 0 & $0 \%$ \\
Grooming & 2 & $4 \%$ & 0 & $0 \%$ \\
Sexual interaction & 2 & $4 \%$ & 0 & $0 \%$ \\
Cuddling & 1 & $2 \%$ & 3 & $6 \%$ \\
Contact walking & 1 & $2 \%$ & 1 & $2 \%$ \\
Sit in close proximity & 1 & $2 \%$ & 0 & $0 \%$ \\
Begging & 1 & $2 \%$ & 0 & $0 \%$ \\
Cofeeding & 0 & $0 \%$ & 1 & $2 \%$ \\
\hline
\end{tabular}

1 